
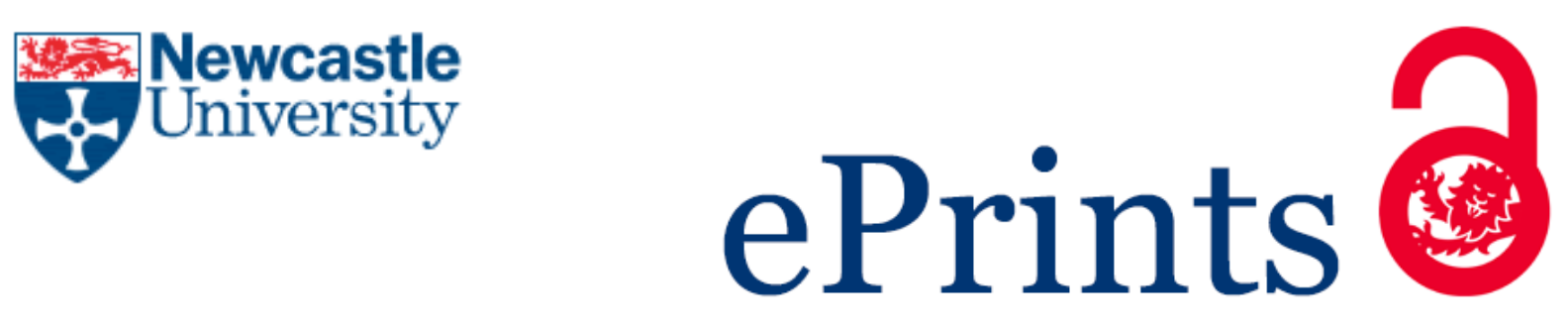

Li L, Gao Y, Yuan Z, Day S, Hu Z.

Dynamic response and power production of a floating integrated wind, wave and tidal energy system.

Renewable Energy 2017,

https://doi.org/10.1016/j.renene.2017.09.080

Copyright:

(C) 2017. This manuscript version is made available under the CC-BY-NC-ND 4.0 license

DOI link to article:

https://doi.org/10.1016/j.renene.2017.09.080

Date deposited:

$03 / 10 / 2017$

Embargo release date:

29 September 2018

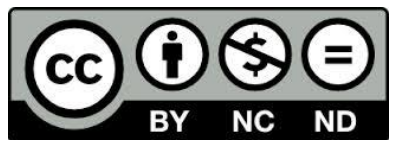

This work is licensed under a

Creative Commons Attribution-NonCommercial-NoDerivatives 4.0 International licence 


\title{
Dynamic Response and Power Production of a Floating Integrated Wind, Wave and Tidal Energy System
}

\author{
Liang $\mathrm{Li}^{\mathrm{a}, \mathrm{b}}$, Yan Gao ${ }^{\mathrm{a},{ }^{*}}$, Zhiming Yuan ${ }^{\mathrm{a}}$, Sandy Day ${ }^{\mathrm{a}}$, Zhiqiang $\mathrm{Hu}^{\mathrm{c}}$ \\ ${ }^{a}$ Department of Naval Architecture, Ocean and Marine Engineering, University of Strathclyde, Glasgow, G4 OLZ,United \\ Kingdom \\ ${ }^{b}$ State Key Laboratory of Ocean Engineering, Shanghai Jiao Tong University, Shanghai, 200240, China \\ ${ }^{c}$ School of Marine Science and Technology, Newcastle University, Newcastle upon Tyne, NE1 7RU, United Kingdom \\ * Corresponding author \\ E-mail address: yan.gao@strath.ac.uk (Yan Gao)
}

\section{Abstract}

This study deals with the hydro-aero-mooring coupled dynamic analysis of a new offshore floating renewable energy system, which integrates an offshore floating wind turbine (OFWT), a wave energy converter (WEC) and tidal turbines. The primary objective is to enhance the power production and reduce the platform motions through the combination of the three types of renewable energy systems. Simulation results show that the combined concept achieves a synergy between the floating wind turbine, the wave energy converter and the tidal turbines. Compared with a single floating wind turbine, the combined concept undertakes reduced surge and pitch motions. The overall power production increases by approximately $22 \%-45 \%$ depending on the environmental conditions. Moreover, the power production of the wind turbine is more stable due to the reduced platform motions and the combined concept is less sensitive to the transient effect induced by an emergency shutdown of the wind turbine.

Keywords: renewable energy, offshore floating wind turbine, wave energy converter, tidal turbine, dynamic response.

\section{Introduction}

Due to the issues like environmental pollution, energy crisis and sustainable development, the exploitation of offshore energy is boosted by the global pursuit of renewable energy. Coastal areas provide the renewable energy sources in the form of wind, sea currents, and waves. Theories and technologies have been developed to exploit these types of offshore renewable energy resources.

Over the last decade, a large number of offshore floating wind turbine concepts have been developed. Statoil [1] proposed a SPAR-buoy floating wind turbine, namely the Hywind concept, which is the first full-scale floating wind turbine that has ever been built. Principle Power installed a 
full-scale 2MW WindFloat prototype near the coast of Portugal [2]. In order to generate valid data for calibration and improvement of current analysis methodology as well as to assess the merits and demerits of different types of floating foundations, the OC4 DeepCwind consortium launched a model test campaign in MARIN. Measurements regarding the global motions, flexible tower dynamics and mooring system responses of a SPAR, a semi-submersible and a TLP foundation were presented and compared [3].

Compared to wind, wave energy is a renewable resource with a higher power density. Various types of WEC systems have been proposed, including the attenuator, the point absorber and the terminator, etc. Recent studies on WEC systems mainly focus on array effects and the control algorithms. Vicente et al. [4] studied the dynamics of arrays of point-absorber WECs with different mooring connections. Engstrom et al. [5] investigated the power variation in a large array of pointabsorbing WECs, the smoothing effect due to the number of devices and their hydrodynamic interactions.

Sea current is increasingly being recognised as a solution to the sustainable generation of electrical power. The majority of tidal turbine designs are based on horizontal axis turbines, similar to those applied in the wind energy industry. Bahaj et al. [6] used blade element momentum (BEM) theory to predict the hydrodynamic performance of a horizontal axis tidal turbine in steady flow and compared the predicted results with experimental measurement. Zhang et al. [7] studied how the hydrodynamic performance of a tidal turbine was affected when installed on a floating platform. They revealed a positive correlation between the oscillation amplitude and the frequency of platform surge motion.

In a site where wind, waves and sea currents coexist, the combination of a floating wind turbine, a wave energy converter and a tidal turbine may be a prospective and economical solution to the full exploitation of offshore renewable energy. Some studies on the combined deployment of wind, wave and tidal energy have been conducted and reported by previous researchers. Aubault et al. [8] incorporated an oscillating-water-column type WEC into a semi-submersible floating wind turbine. In their work, the theory of such modelling was summarized and it was shown that the overall economic cost could be reduced by sharing the mooring and power infrastructure. Muliawan et al. [9] studied the dynamic response and the power performance of a combined SPAR-type floating wind turbine and coaxial floating wave energy converter in operational conditions. The analysis was performed in several operational conditions and the simulation results indicated that a synergy between wind and wave energy generation was achieved. Further experimental and numerical studies of the hybrid concept in survival mode were conducted by Wan et al. [10]. Several phenomena were observed in their model tests, such as wave slamming, Mathieu instability and vortex induced motions. Michailides et al. [11] incorporated a flap-type WEC to a semi-submersible floating wind turbine and investigated the effect of WECs on the response of the integrated system. Their study showed that the combined operation of the rotating flaps resulted in an increase of the produced power without affecting the critical response quantities of the semi-submersible platform significantly. Bachynski 
and Moan [12] studied the effects of 3 point absorber WECs on a TLP floating wind turbine in operational and 50-year extreme environmental conditions, in terms of power take-off, structural loads and platform motions. According to their research, reduced surge and pitch motions were observed in operational conditions while increased pitch motions and tendon tension variations were observed in extreme conditions.

In this study, an integrated floating renewable energy concept referred as 'Hywind-WavebobNACA 638xx Combination' (HWNC) is proposed by combing a SPAR-type floating wind turbine, a point absorber-type wave energy converter and tidal turbines. Aero-hydro-mooring coupled simulations are performed to investigate the performance of the HWNC, in terms of platform motions, power production and mooring line tension. No control scheme is applied in the modelling and the structural dynamics is neglected as well. The HWNC is compared with a single SPAR-type floating wind turbine in three operational conditions (below-rated, rated and over-rated) as well as emergency shutdown. It will examine whether the performance of the HWNC can be improved with the installation of the WEC and the tidal turbines.

\section{Concept description}

The combined concept proposed in this study is inspired by the SPAR-type floating wind turbine OC3 Hywind [13], the two-body floating WEC 'Wavebob' and the NACA 638xx aerofoil series. The sketch of each component is displayed in Fig. 1.
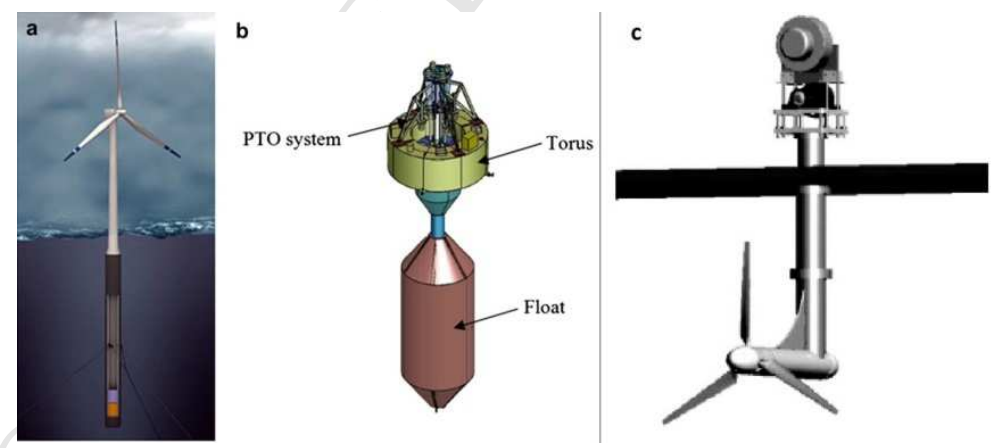

Fig. 1. (a) Hywind [1]; (b) Wavebob [9]; (c) Tidal turbine with application of the NACA 638xx series [6].

In the HWNC concept (see Fig. 2), the float component of the Wavebob is replaced by the SPAR platform and the torus is connected directly to the platform through mechanical facilities. The WEC is designed to move only in heave mode relative to the platform and no relative surge, sway, roll, pitch and yaw motions are allowed. Tidal turbines are installed to harvest energy from the sea current. The main dimensions of the HWNC concept are presented in Table 1 and the mass properties of each subsystem are listed in Table 2. 


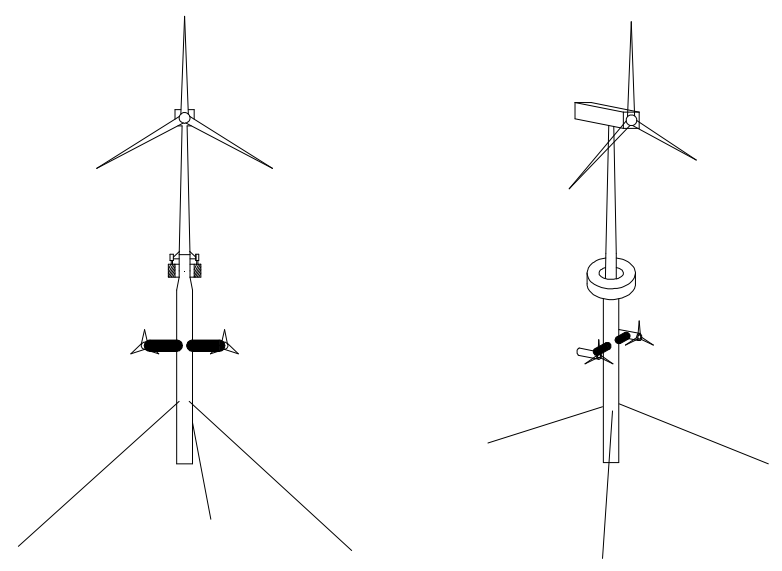

96

97

98

99

Table 1

Fig. 2. HWNC concept.

Main dimensions of the HWNC.

\begin{tabular}{lll}
\hline HWNC & Total draft & $120 \mathrm{~m}$ \\
\hline \multirow{4}{*}{ Platform } & Tower base above still water level (SWL) & $10 \mathrm{~m}$ \\
& Depth to top of taper below SWL & $4 \mathrm{~m}$ \\
& Depth to bottom of taper below SWL & $12 \mathrm{~m}$ \\
& Platform diameter above taper & $6.5 \mathrm{~m}$ \\
\multirow{2}{*}{ Wavebob } & Platform diameter below taper & $9.4 \mathrm{~m}$ \\
\hline \multirow{2}{*}{ Tidal turbine } & Height & $8 \mathrm{~m}$ \\
& Outer diameter & $20 \mathrm{~m}$ \\
\hline \multirow{2}{*}{ Inner diameter } & $10 \mathrm{~m}$ \\
\hline
\end{tabular}

Table 2

102 Mass properties of subsystem.

\begin{tabular}{lll}
\hline & Item & Value \\
\hline \multirow{4}{*}{ Hywind } & Total mass & $7,813,130 \mathrm{~kg}$ \\
& Centre of mass (CM) below SWL & $84.32 \mathrm{~m}$ \\
& Roll inertia about CM & $6,541,300,000 \mathrm{~kg} \cdot \mathrm{m}^{2}$ \\
& Pitch inertia about CM & $6,541,300,000 \mathrm{~kg} \cdot \mathrm{m}^{2}$ \\
& Yaw inertia about CM & $164,230,000 \mathrm{~kg} \cdot \mathrm{m}^{2}$ \\
\hline \multirow{5}{*}{ Wavebob } & Total mass & $966,900 \mathrm{~kg}$ \\
& CM below SWL & $0 \mathrm{~m}$ \\
& Roll inertia about CM & $3,139,900 \mathrm{~kg} \cdot \mathrm{m}^{2}$ \\
& Pitch inertia about CM & $3,139,900 \mathrm{~kg} \cdot \mathrm{m}^{2}$ \\
& Yaw inertia about CM & $6,022,200 \mathrm{~kg} \cdot \mathrm{m}^{2}$ \\
\hline
\end{tabular}

103

The HWNC is operated at sea site with a water depth of $320 \mathrm{~m}$ and moored by three slack catenary lines. The fairleads are connected to the platform at $70 \mathrm{~m}$ below the still water level. Fig. 4 displays the configuration of the mooring system. The three lines are oriented at $60^{\circ}, 180^{\circ}$, and $300^{\circ}$ about the vertical axis. The relevant properties of the mooring lines are listed in Table 3. 
Table 3

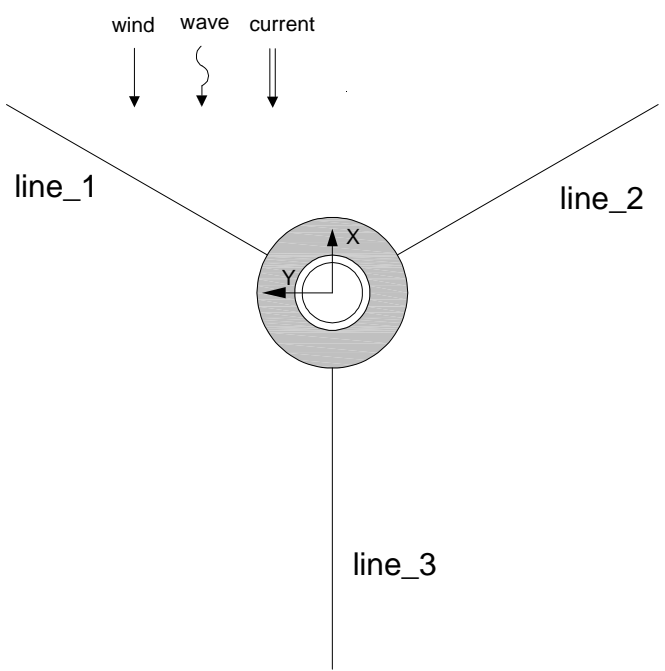

Mooring line properties.

\begin{tabular}{ll}
\hline Item & Value \\
\hline Depth to anchors & $320 \mathrm{~m}$ \\
Depth of fairleads & $70 \mathrm{~m}$ \\
Radius to anchors & $853.87 \mathrm{~m}$ \\
Radius to fairleads & $5.2 \mathrm{~m}$ \\
Unstretched mooring line length & $902.2 \mathrm{~m}$ \\
Mooring line diameter & $0.09 \mathrm{~m}$ \\
Equivalent mooring line mass density & $77.7066 \mathrm{~kg} / \mathrm{m}$ \\
Equivalent mooring line extensional stiffness & $384,243,000 \mathrm{~N}$ \\
\hline
\end{tabular}

\section{Modelling set-up}

The simulation code, which is expanded to include hydrodynamic interactions and mechanical couplings, is based on the work of $\mathrm{Li}$ et al. [14]. Hydrodynamic terms are addressed within the framework of linear potential flow theory. Mechanical connections are simulated through the application of a multi-body dynamics model. Aerodynamic loads are calculated by using blade element momentum (BEM) theory and a dynamic wake model is incorporated to take the unsteadiness of the inflow into account. A lumped-mass approach is applied to model the mooring line dynamics.

\subsection{Motion equation}

The time domain motion equations of two floating bodies in waves, considering their hydrodynamic interactions, are expressed by Eq. (1).

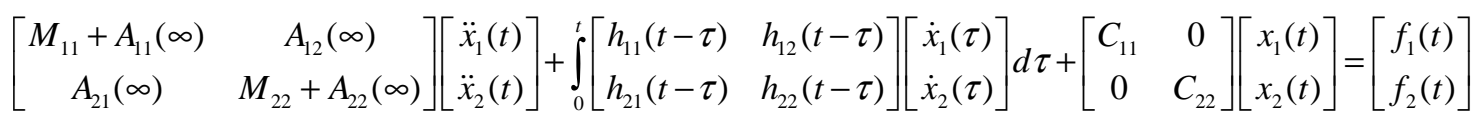

in which $A_{i j}(\infty)$ is the added mass matrix at infinite frequency; $x_{i}(t), \dot{x}_{i}(t)$ and $\ddot{x}_{i}(t)$ are the 
can be obtained from either the added mass or the potential damping. $A_{12}(\infty), A_{21}(\infty), h_{12}(\tau)$ and $h_{21}(\tau)$ represent the hydrodynamic interactions between the two floating bodies. $C_{i j}$ is the restoring stiffness. $f_{i}(t)$ is the resultant external excitation force in time domain, involving the linear wave excitation force, the drag force, the thrust force on the wind turbine, the thrust forces on the tidal turbines and the mooring tension.

131

132

133

134

135

136

\subsection{Hydrodynamics}

The frequency domain hydrodynamic coefficients of the two bodies considered in the HWNC are firstly calculated with WAMIT [15]. Fig. 4 displays the mean wetted surface panel model of the HWNC. Since the tidal turbines are small components compared with the SPAR platform, they are excluded in the panel model and their contributions to the hydrodynamic coefficients of the HWNC is neglected as a result.
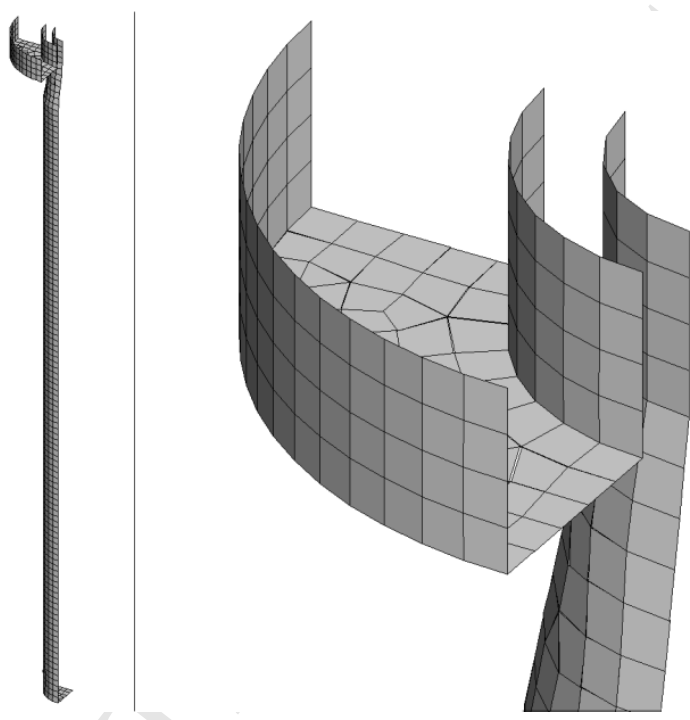

Fig. 4. Mean wetted surface panel model of HWNC.

The time series of the linear wave excitation force is represented with the transfer function,

$$
f_{e x t}(t)=\operatorname{Re}\left[\sum_{i=1}^{N} H\left(\omega_{i}\right) e^{i\left(\omega_{i} t+\theta_{i}\right)} \sqrt{2 S\left(\omega_{i}\right) d \omega}\right]
$$

where $H(\omega)$ is the first order wave excitation force transfer function; $\omega$ is the incident wave oscillating frequency; $\theta$ is the random phase angle; $S(\omega)$ is the wave spectrum used to describe the irregular waves.

The modelling of the drag force is based on the combination of Morison's equation and strip theory

$$
f_{d r a g}(t)=\sum_{i=1}^{N} \frac{1}{2} \rho C_{d} A_{i}\left(v_{i}(t)-\dot{x}_{i}(t)\right)\left|v_{i}(t)-\dot{x}_{i}(t)\right|
$$

where $C_{d}$ is the drag coefficient, $A_{i}$ is the characteristic area of element $i, v_{i}$ is the fluid particle velocity at element $i$. 
Instead of representing the radiation force $f_{\text {rad }}(t)$ with a convolution integral, a state-space model is

151

152 used to enhance the calculation efficiency. Using a state-space model, the radiation force can be expressed by a set of differential equations,

$$
\begin{aligned}
& f_{\text {rad }}(t)=C \cdot u(t)+D \cdot \dot{x}(t) \\
& \dot{u}(t)=A \cdot u(t)+B \cdot \dot{x}(t)
\end{aligned}
$$

where $u(t)$ is an $n$-dimensional column vector, with $n$ being the number of states. $\dot{x}(t)$ is the input to the state-space model, namely the velocity vector of the floating body. $A, B, C$ and $D$ are all constant matrices characterizing the state-space model. The detailed procedure of transforming a convolution integral to a state-space formula can be found in [16].

\subsection{Aerodynamics}

The calculation of aerodynamic loads is based on BEM method. For a floating wind turbine, the inflow seen by the rotor is unsteady due to the platform motions and it is necessary to use a modified BEM method to compute realistically the aerodynamic behaviour of the wind turbine. The unsteady BEM model proposed by Hansen [17] is used to consider the unsteady effect.

After the steady induced wind velocity is obtained with steady BEM method, a quasi-steady induced wind velocity is calculated

$$
W_{q s}=\left[\frac{-B L \cos \phi}{4 \pi \rho r F\left|\overline{V_{0}}+f_{g} \vec{n}\left(\vec{n} \cdot \overline{W_{0}}\right)\right|}, \frac{-B L \sin \phi}{4 \pi \rho r F\left|\overrightarrow{V_{0}}+f_{g} \vec{n}\left(\vec{n} \cdot \overrightarrow{W_{0}}\right)\right|}, 0\right]
$$

where $\vec{n}=(0,0,-1) ; \vec{V}_{0}$ is the inflow speed; $\vec{W}_{0}$ is the induced velocity obtained with steady BEM method; $\phi$ is the induced velocity angle; $L$ stands for the lift force obtained with steady BEM method; $B$ is the number of blades; $r$ is the local radius of blade section. $F$ is the Frandtl's tip loss factor used to correct the effect arising from finite number of blades.

$$
F=\frac{2}{\pi} \cos ^{-1}\left(e^{-f}\right), f=\frac{2}{\pi} \frac{R-r}{R \sin \phi}
$$

$R$ is the radius of the blade. $f_{g}$ is commonly known as Glauert correction, an empirical relationship between the thrust force and the axial induction factor $a$.

$$
f_{g}=\left\{\begin{array}{c}
1, a \leq 0.2 \\
\frac{0.2}{a}\left(2-\frac{0.2}{a}\right), a>0.2 \quad a=\frac{W_{x}}{\left|\overrightarrow{V_{0}}\right|}
\end{array}\right.
$$

The quasi-static induced wind velocity $W_{q s}$ is afterwards filtered by the dynamic wake model proposed by S. Øye [18],

$$
\begin{gathered}
W_{\mathrm{int}}+\tau_{1} \frac{d W_{\mathrm{int}}}{d t}=W_{q s}+k \cdot \tau_{1} \frac{d W_{q s}}{d t} \\
W+\tau_{2} \frac{d W}{d t}=W_{\mathrm{int}}
\end{gathered}
$$


where $W_{\text {int }}$ is an intermediate value and $W$ is the final filtered value. $k=0.6 . \tau_{1}$ and $\tau_{2}$ are constant coefficients depending on the rotor radius and the incoming wind speed.

When the final induced inflow speed is estimated, the relative inflow speed and thus the aerodynamic loads can be calculated using lift coefficient $C_{l}$ and drag coefficient $C_{d}$

$$
f_{x}=\frac{1}{2} \rho V_{r e l}^{2} c C_{l} \cos \alpha+\frac{1}{2} \rho V_{r e l}^{2} c C_{d} \sin \alpha
$$

$$
f_{y}=\frac{1}{2} \rho V_{r e l}^{2} c C_{l} \sin \alpha-\frac{1}{2} \rho V_{r e l}^{2} c C_{d} \cos \alpha
$$

where $\rho$ is the air density; $c$ is the chord length, $\alpha$ is the angle of attack. Then the total thrust force and the rotor power production is given by

$$
\begin{aligned}
& f_{\text {thrust }}=\sum_{i=1}^{N} f_{x}^{i} \\
& P_{\text {wind }}=\sum_{i=1}^{N} f_{y}^{i} r^{i} \Omega
\end{aligned}
$$

$\Omega$ is the rotor rotation speed and $r^{i}$ is the radius of blade element $i$. It should be noted that $P_{\text {wind }}$ stands for the rotor power output rather than the generator power output.

\subsection{Power take-off system}

The WEC is designed to move only in heave mode relative to the platform and no surge, sway, roll, pitch and yaw motions are allowed. Such configuration is implemented through the application of a multi-body dynamics model. The WEC relies on a power take-off (PTO) system to transform the relative heave motion into electric power. An ideal spring-damper model is applied to represent the PTO system. The damping coefficient $B$ and the stiffness coefficient $K$ is set to $B=800 \mathrm{kN} \cdot \mathrm{s} / \mathrm{m}$ and $K$ $=5 \mathrm{kN} / \mathrm{m}$, respectively. The power produced by the PTO is given by

$$
P_{\text {wave }}=K \cdot x_{r e l} \dot{x}_{r e l}+B \cdot \dot{x}_{r e l}^{2}
$$

\subsection{Mooring system}

The dynamics of the mooring lines is modelled using a lumped-mass approach. As shown in Fig. 5 , the mooring line is divided into a series of evenly-sized segments, which are represented by connected nodes and spring \& damper systems. Each segment is divided into two components and the properties are assigned and lumped to the two nodes at each end of that segment, respectively. The connections between adjacent nodes are represented by damper-spring systems. In this study, the lumped-mass approach merely models the axial properties of the mooring lines while the torsional and bending properties are neglected. The effects of wave kinematics and any other external loads on the lines are also ignored in the lumped-mas model. Details of the basic equations and the calculation procedures can be found in [19]. 
206

207

208

209

210

211

212

213

214

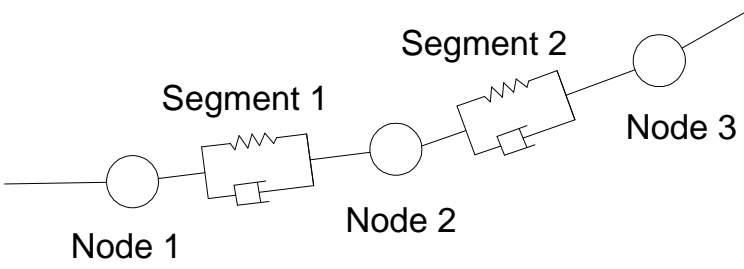

Fig. 5. Lumped-mass model of mooring line.

\subsection{Tidal turbine}

The unsteady BEM method presented in Section 3.3 is used to calculate sea current forces acting on the tidal turbines. The tidal turbine blades are based on the NACA_8xx aerofoil series. The particulars of the blades are listed in Table 4.

Table 4

Particulars of tidal turbine blade.

\begin{tabular}{ccccc}
\hline$r(\mathrm{~m})$ & Aerofoil & Chord $(c / R)$ & Pitch $(\mathrm{deg})$ & Thickness $(t / c)$ \\
\hline 2 & NACA_812 & 0.125 & 15.0 & 0.240 \\
3 & NACA_812 & 0.116 & 9.5 & 0.207 \\
4 & NACA_815 & 0.106 & 6.1 & 0.187 \\
5 & NACA_815 & 0.097 & 3.9 & 0.176 \\
6 & NACA_818 & 0.088 & 2.4 & 0.166 \\
7 & NACA_818 & 0.078 & 2.5 & 0.156 \\
8 & NACA_821 & 0.069 & 0.9 & 0.146 \\
9 & NACA_821 & 0.059 & 0.4 & 0.136 \\
10 & NACA_824 & 0.050 & 0.0 & 0.126 \\
\hline
\end{tabular}

$215 \quad 4 . \quad$ Validation

\subsection{Validation of wind turbine}

Since the loads acting on the tidal turbines and the wind turbine are both calculated with the unsteady BEM method discussed in Section 3.3, only the wind turbine is validated here. The steady thrust force and the rotor power output of the wind turbine are simulated with a set of wind speeds. The rotor speed and blade pitch angle corresponding to each wind speed are listed in Table 5.

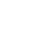


$230 \quad$ Rotor speeds and blade pitch angles with different wind speeds

\begin{tabular}{ccc}
\hline Wind speed $(\mathrm{m} / \mathrm{s})$ & Rotor speed $(\mathrm{rpm})$ & Blade pitch angle $(\mathrm{deg})$ \\
\hline 4 & 7.27 & 0 \\
5 & 7.40 & 0 \\
6 & 7.96 & 0 \\
7 & 8.52 & 0 \\
8 & 9.08 & 0 \\
9 & 10.35 & 0 \\
10 & 11.34 & 0 \\
11.4 & 12.1 & 0 \\
12 & 12.1 & 3.73 \\
13 & 12.1 & 6.51 \\
14 & 12.1 & 8.55 \\
15 & 12.1 & 10.36 \\
16 & 12.1 & 12 \\
\hline
\end{tabular}

231

232

233

234

235

236

237

238

239

240

241

242

243

244

245

Fig. 6 displays the comparisons of the simulated thrust force and rotor power output with the prototype values. It should be noted that the rated rotor power output of the NREL 5WM baseline wind turbine is $5.3 \mathrm{WM}$ (The rated generator power output is $5 \mathrm{MW}$ ).
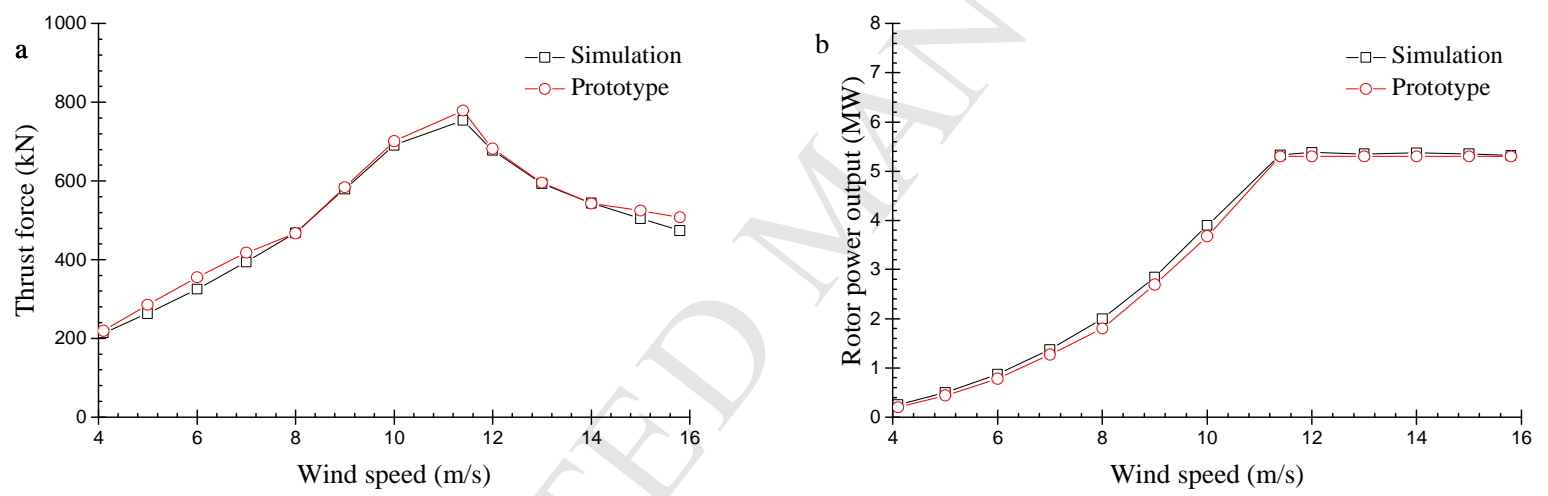

Fig. 6. Validation of simulated wind turbine thrust force and rotor power output against prototype value. (a) thrust force; (b) rotor power output.

To validate the unsteady aerodynamic modelling, the wind turbine thrust force is simulated under a set of unsteady winds and the simulation results are compared with those obtained by FAST. The speed of unsteady wind is defined by

$$
V(t)=V_{0}+\sin (\omega t)
$$

where $V_{0}$ is the mean wind speed and $\omega$ is the varying frequency. The control module in FAST is switched off so that the rotor speed and the blade pitch angle are fixed in the simulations. Fig. 7 displays time series of the unsteady wind turbine thrust forces predicted by the simulation tool and FAST. 

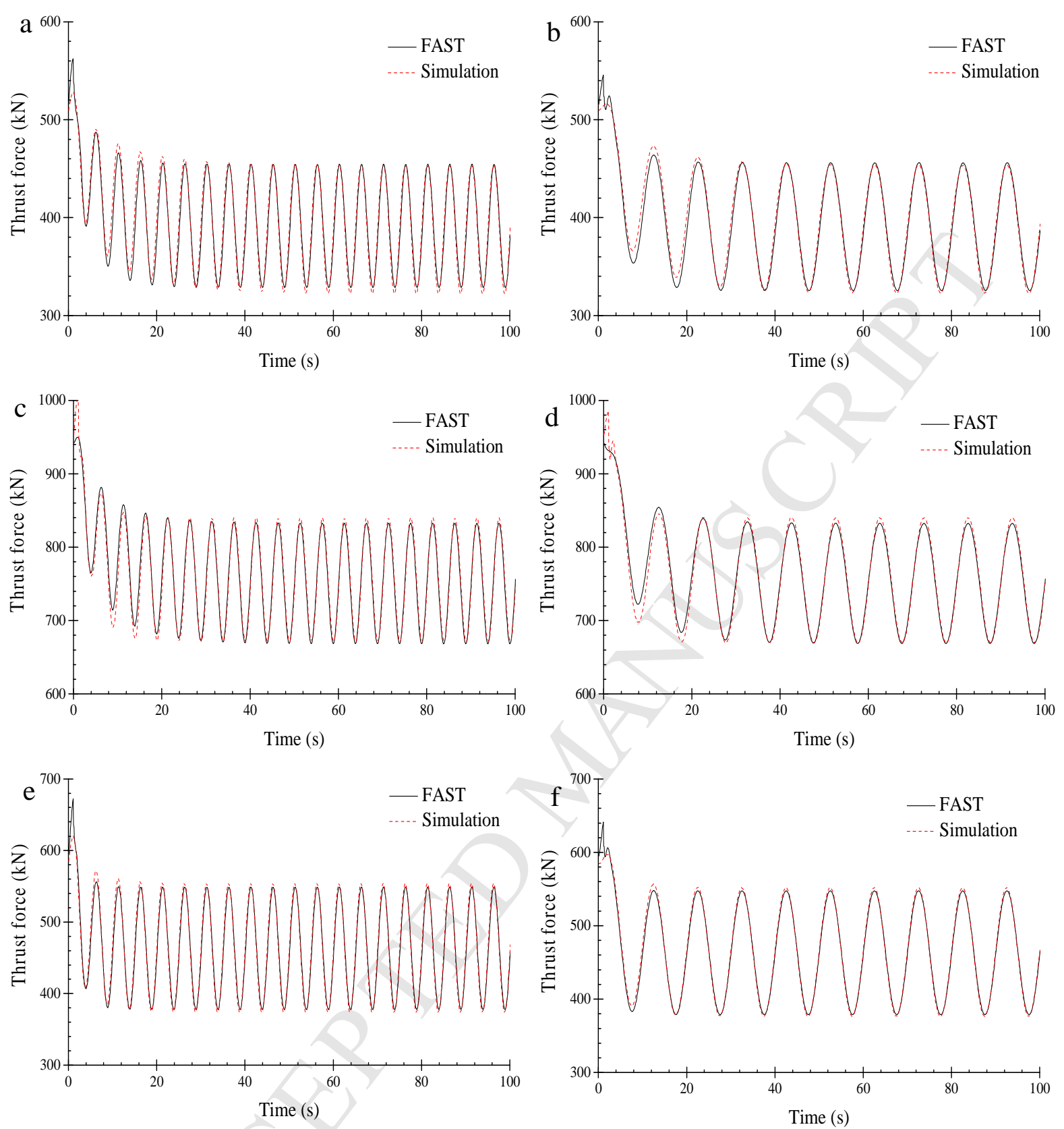

Fig. 7. Times series of unsteady wind turbine thrust forces. (a) $V_{0}=8 \mathrm{~m} / \mathrm{s}, \omega=1.26 \mathrm{rad} / \mathrm{s} ;(\mathrm{b}) V_{0}=8 \mathrm{~m} / \mathrm{s}, \omega=0.63 \mathrm{rad} / \mathrm{s} ;(\mathrm{c})$ $V_{0}=11.4 \mathrm{~m} / \mathrm{s}, \omega=1.26 \mathrm{rad} / \mathrm{s} ;$ (d) $V_{0}=11.4 \mathrm{~m} / \mathrm{s}, \omega=0.63 \mathrm{rad} / \mathrm{s} ;$ (e) $V_{0}=14 \mathrm{~m} / \mathrm{s}, \omega=1.26 \mathrm{rad} / \mathrm{s}$; (f) $V_{0}=14 \mathrm{~m} / \mathrm{s}, \omega=0.63$ $\mathrm{rad} / \mathrm{s}$;

\subsection{Validation of platform-wind turbine couplings}

The model test of the Hywind floating wind turbine conducted by Koo et al. [20] is used to validate the numerical modelling of platform-wind turbine couplings. White noise waves were generated in the model test to get the response amplitude operator (RAO) of platform motions in the presence of rated wind turbine thrust force. The same procedure is employed in the numerical simulation. Fig. 8 compares the RAOs acquired by the simulation tool and the experiment. Some discrepancies are observed between the model test data and simulation results, which are mainly attributed to altered performance of the wind turbine in the experimental environment [21]. 

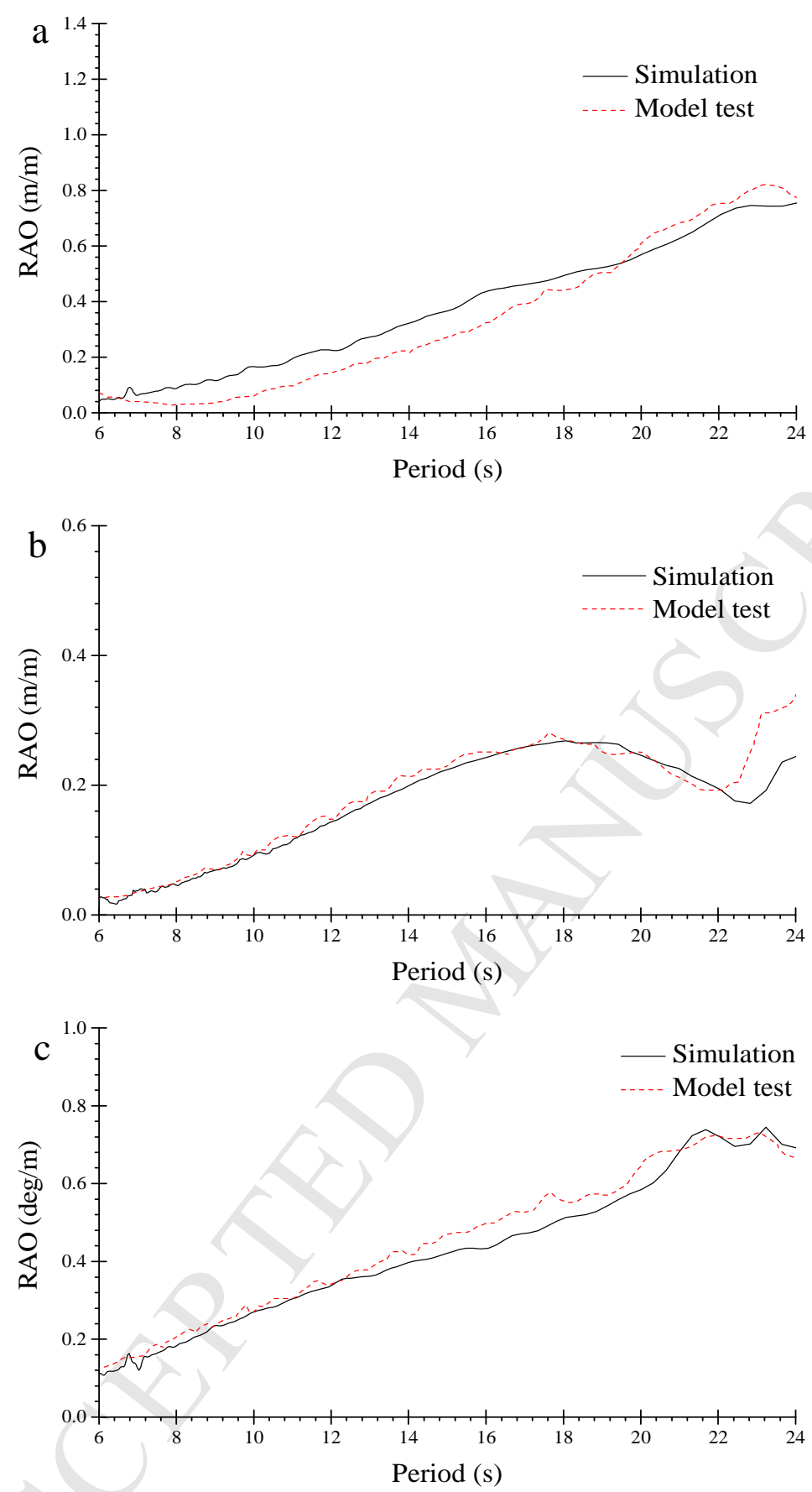

Fig. 8. RAOs of platform motions. (a) surge motion; (b) heave motion; (c) pitch motion.

\subsection{Validation of platform-WEC couplings}

The simulation code is compared with WEC-Sim [22], a wave energy converter simulator developed under the collaboration between the National Renewable Energy Laboratory (NREL) and the Sandia National Laboratories, to validate the modelling of platform-WEC couplings. Since WECSim cannot simulate any aerodynamic loads or sea current loads, waves-only conditions will be considered in the comparison.

266 Simulations are performed in a series of unit regular wave conditions to get the RAO for the motions of the platform and the WEC. It should be noted that the drag force modelling in the two 
simulation codes are different, so the drag force is neglected to focus on the comparison. Fig. 9

269 displays the RAOs for the motions of the platform and the WEC.

a

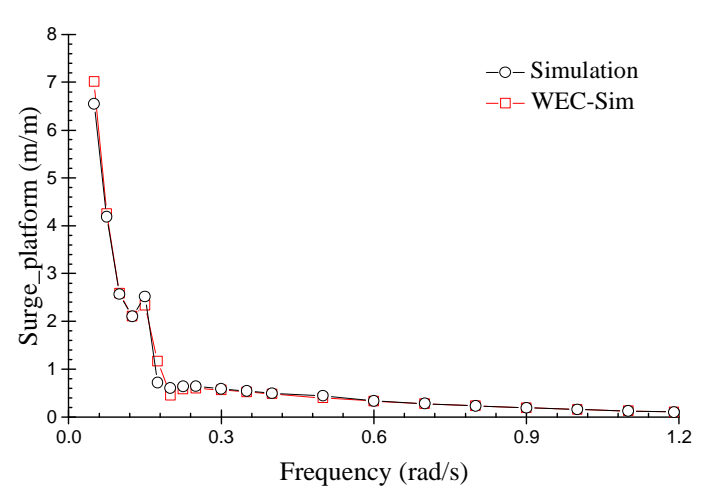

c

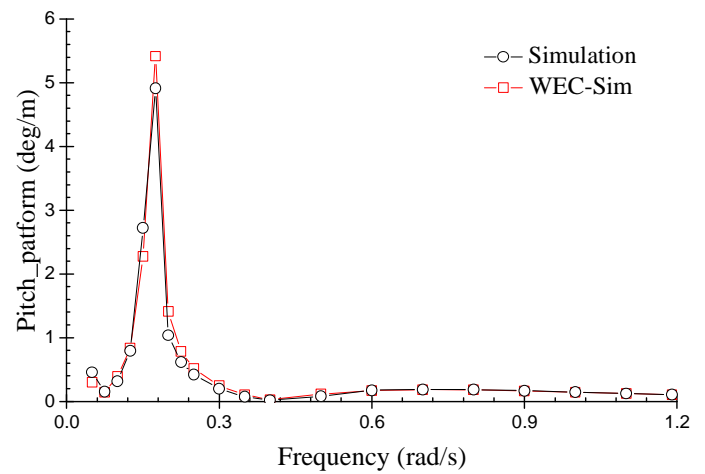

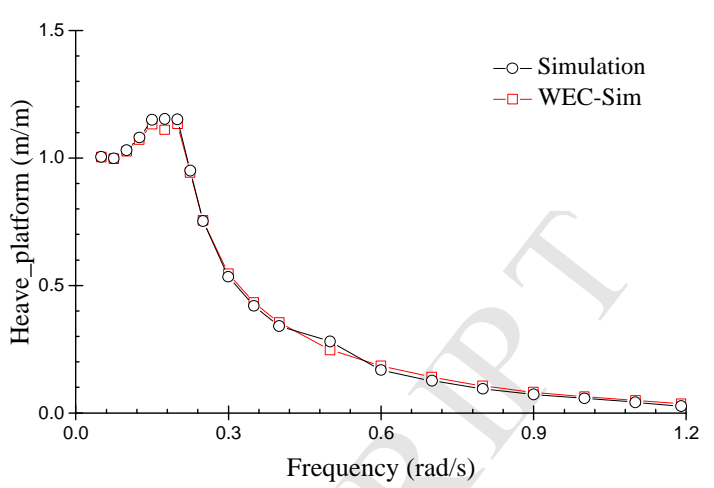

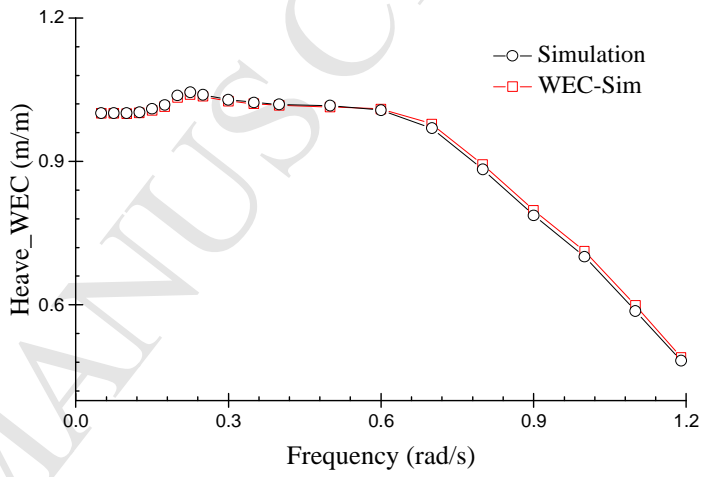

Fig. 9. RAOs for the motions of platform and WEC. (a) platform surge motion; (b) platform heave motion; (c) platform pitch motion; (d) WEC heave motion.

\section{Numerical simulation and comparison study}

This section will examine the dynamic performance of the HWNC, in terms of platform motions, power production and mooring line tension. Comparison will be made with the Hywind to investigate whether the HWNC can behave better with the installation of the WEC and the tidal turbines. The environmental conditions considered in the simulations are listed in Table 6. The waves, wind and sea currents all propagate along negative $X$ direction (see Fig. 3). The irregular incident waves are described with the Pierson Moskowitz spectrum. The simulation duration is $4000 \mathrm{~s}$ and only data of the last $3600 \mathrm{~s}$ will be selected to get rid of the transient effect arising in the initial simulation stage.

(1)

4

5

6




\begin{tabular}{ccccc}
\hline \multirow{2}{*}{ Simulation Case } & \multicolumn{2}{c}{ Wave condition } & \multirow{2}{*}{ Wind velocity } & \multirow{2}{*}{ Sea current speed } \\
\cline { 2 - 3 } & $H_{s}$ & $T_{p}$ & & \\
\hline LC1 & $2.3 \mathrm{~m}$ & $10 \mathrm{~s}$ & $8 \mathrm{~m} / \mathrm{s}$ & $1.8 \mathrm{~m} / \mathrm{s}$ \\
LC2 & $3.5 \mathrm{~m}$ & $13 \mathrm{~s}$ & $11.4 \mathrm{~m} / \mathrm{s}$ & $2 \mathrm{~m} / \mathrm{s}$ \\
LC3 & $5.2 \mathrm{~m}$ & $17.5 \mathrm{~s}$ & $14 \mathrm{~m} / \mathrm{s}$ & $2.2 \mathrm{~m} / \mathrm{s}$ \\
\hline
\end{tabular}

\subsection{Identification of natural periods}

291 The natural periods of the HWNC will vary with the installation of the WEC and the tidal turbines.

292 Free decay motions are therefore simulated to identify the natural periods. In order to demonstrate the

293 effects of hydrodynamic interactions and mechanical couplings, the WEC is free to move along heave 294 mode relative to the platform in the free decay simulation.

295 The time series of free decay motions are plotted in Fig. 10 and Table 7 lists the natural periods of 296 the HWNC and the Hywind. The surge natural period of the HWNC is increased from $125.0 \mathrm{~s}$ to $297129.4 \mathrm{~s}$ and its pitch natural period is increased from $22.5 \mathrm{~s}$ to $28.9 \mathrm{~s}$. On the contrary, the natural 298 period of heave mode is shortened, dropping from $31.2 \mathrm{~s}$ to $29.3 \mathrm{~s}$. By investigating the heave decay 299 motion, it is found that the HWNC decays much more rapidly. It is mainly caused by the damping $(B$ $300=800 \mathrm{kN} \cdot \mathrm{s} / \mathrm{m}$ ) of the PTO facility. From an energy conservation point of view, the relative heave 301 motion between the WEC and the platform is transformed to electricity power by the PTO facility and the kinetic energy of the HWNC will dissipate rapidly as a result. 
a

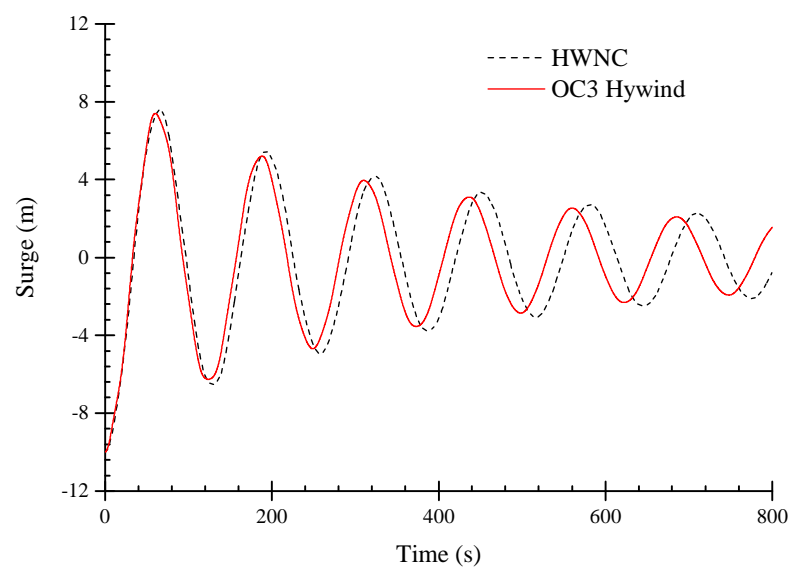

b

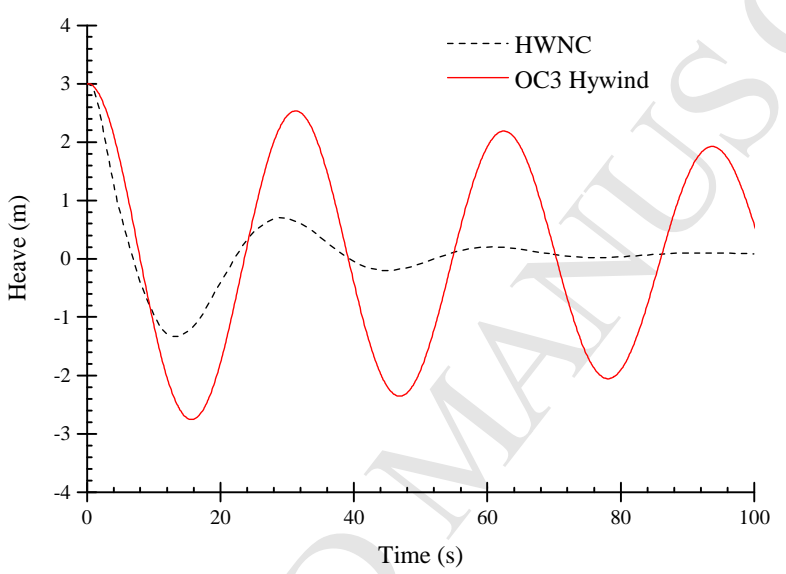

$\mathrm{c}$

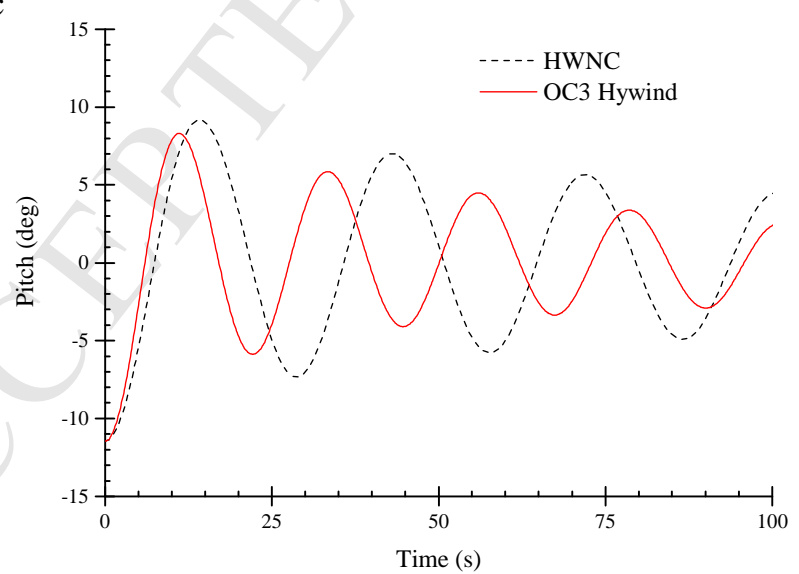

Fig. 10. Time series of platform free decay motions. (a) surge free decay motion; (b) heave free decay motion; (c) pitch free decay motion.

Table 7

308 Natural periods of HWNC and OC3 Hywind

\begin{tabular}{lll}
\hline & HWNC & OC3 Hywind \\
\hline Surge & $129.4 \mathrm{~s}$ & $125.0 \mathrm{~s}$ \\
Heave & $29.3 \mathrm{~s}$ & $31.2 \mathrm{~s}$ \\
Pitch & $28.9 \mathrm{~s}$ & $22.5 \mathrm{~s}$ \\
\hline
\end{tabular}




\subsection{Platform motions}

311 The statistical results of platform motions are listed in Table 8. It is shown that the platform is 312 pushed further away from the initial equilibrium position due to the sea current forces acting on the 313 tidal turbines. It inherently indicates that the mooring lines will undertake more tension to restrain the 314 platform against the wind force and the sea current force. Compared with the platform, the standard 315 deviation of the WEC's heave motion is much larger in the three simulation cases. It is 316 straightforward to understand this since the water plane area of the WEC is larger and its mass is 317 smaller. Fig. 11 displays the fast Fourier transform (FFT) analysis results of the platform motions for 318 the simulation case LC2. It is shown that the HWNC performs better in terms of surge and pitch 319 motions. The reduced surge and pitch motions are beneficial to the wind turbine power output. It will 320 be clarified in the following section that the wind turbine power output becomes more stable due to 321 the reduced surge and pitch platform motions.

\section{Table 8}

323 Statistical results of platform motions

\begin{tabular}{ccccccccc}
\hline & & \multicolumn{3}{c}{ HWNC } & WEC & \multicolumn{3}{c}{ OC3 Hywind } \\
\cline { 3 - 8 } & & $\begin{array}{c}\text { Surge } \\
(\mathrm{m})\end{array}$ & $\begin{array}{c}\text { Heave } \\
(\mathrm{m})\end{array}$ & $\begin{array}{c}\text { Pitch } \\
(\mathrm{deg})\end{array}$ & $\begin{array}{c}\text { Heave } \\
(\mathrm{m})\end{array}$ & $\begin{array}{c}\text { Surge } \\
(\mathrm{m})\end{array}$ & $\begin{array}{c}\text { Heave } \\
(\mathrm{m})\end{array}$ & $\begin{array}{c}\text { Pitch } \\
(\mathrm{deg})\end{array}$ \\
\hline \multirow{5}{*}{ LC1 } & Max & -23.24 & -0.10 & -1.83 & 1.99 & -9.58 & 0.07 & -0.45 \\
& Min & -24.34 & -0.63 & -2.49 & -1.72 & -13.39 & -0.31 & -2.86 \\
& Mean & -23.78 & -0.37 & -2.18 & 0.00 & -11.72 & -0.11 & -1.79 \\
& Std.dev & 0.17 & 0.09 & 0.09 & 0.53 & 0.26 & 0.05 & 0.27 \\
\cline { 2 - 8 } LC2 & Max & -33.82 & -0.03 & -2.98 & 2.89 & -21.08 & 0.13 & -1.11 \\
& Min & -36.69 & -1.39 & -3.81 & -2.85 & -27 & -0.64 & -4.92 \\
& Mean & -35.22 & -0.73 & -0.34 & 0.00 & -24 & 0.27 & -3.00 \\
& Std.dev & 0.44 & 0.21 & 0.12 & 0.86 & 0.99 & 0.12 & 0.63 \\
\cline { 2 - 8 } & Max & -27.18 & 0.97 & -1.64 & 4.49 & -7.52 & 0.75 & 2.93 \\
LC3 & Min & -30.72 & -1.94 & -2.95 & -3.98 & -21.41 & -1.16 & -7.72 \\
& Mean & -29.08 & -0.46 & -2.33 & 0.00 & -14.68 & -0.12 & -1.85 \\
& Std.dev & 0.58 & 0.48 & 0.21 & 1.29 & 2.29 & 0.27 & 1.54 \\
\hline
\end{tabular}


a

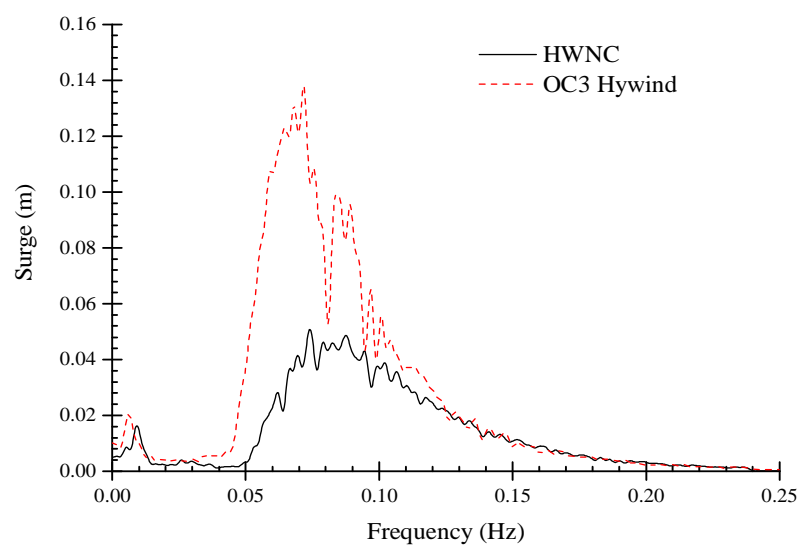

b

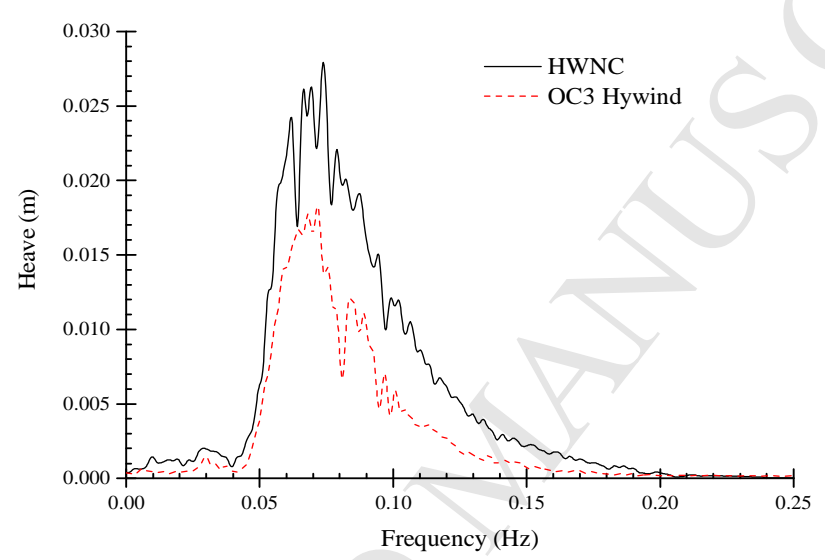

$\mathrm{c}$

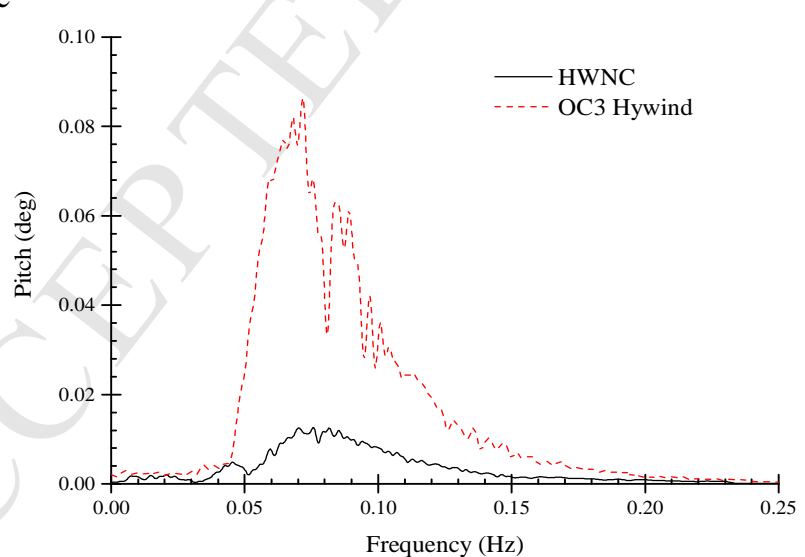

Fig. 11. FFT analysis of platform motions, LC2. (a) surge motion; (b) heave motion; (c) pitch motion.

The reduction of surge and pitch motions is mainly attributed to the tidal turbines, which produce 330 an extra damping. Since the sea current propagates along negative $X$ direction, the thrust force acting on the tidal turbine rotor can be approximated by,

$$
T(\dot{x})=-C_{T} \cdot \frac{1}{2} \rho \pi R^{2}\left(U_{0}+\dot{x}\right)^{2}
$$


where $C_{T}$ is the thrust force coefficient, $U_{0}$ the is sea current speed. Applying Taylor expansion at $\dot{x}=$ 0 , the following series is derived,

$$
T(\Delta \dot{x}+0)=T(0)-C_{T} \rho \pi R^{2} U_{0} \Delta \dot{x}-C_{T} \rho \pi R^{2} U_{0} \Delta \dot{x}^{2}+O\left(\Delta \dot{x}^{2}\right)
$$

The first term is a constant component, which only influences the mean position of the platform. The third term is of second-order and can be regarded as small compared to the first-order term. The second term is a damping term which helps to reduce the platform motions. Eq. 15 illustrates that although the tidal turbine thrust force pushes the platform more far from the initial equilibrium position and may induce larger mooring line tension, it produces a damping component which helps to reduce the platform motions.

In spite of the improved surge and pitch motions, the heave motion of the HWNC becomes worse. The increased heave motion is mainly caused by the WEC, which augments the water plane area of the system significantly. It means that the vertical wave excitation force applying on the system will become much larger. Although the worsened heave motion will have limited influence on the wind turbine power output, it is very likely to lead to unfavourable structural force at critical connections, such as the tower base and the tower top. Besides, the mooring line response may also increase.

\subsection{Power production}

The statistical results of the power production are summarized in Table 9. The wind turbine power production of the HWNC is just reduced slightly (less than 3\%). It's worth mentioning again that no control scheme is included in the study to tune the power output. Consequently, the average power productions in the three operational conditions are different from the design values. The contributions from the WEC and the tidal turbines are considerable. Compared with the Hywind, the total power production of the HWNC is increased by $45 \%, 22 \%$ and $28 \%$ in below-rated, rated and over-rated operational conditions. The power output tends to become unstable when the sea state becomes severe, and this trend is applicable to both the HWNC and the Hywind. Due to the aero-hydro coupling, the unsteadiness of the inflow seen by the rotor will increase in a severe sea state. Consequently, the variation of the power output becomes significant.

\section{Table 9}

Statistical results of power production.

\begin{tabular}{cccccc}
\hline & & \multicolumn{3}{c}{ HNCW } & \multirow{2}{*}{ OC3 Hywind } \\
\cline { 3 - 5 } & & Wind turbine & WEC & Tidal turbine & \\
\hline \multirow{2}{*}{ LC1 } & Mean (MW) & 2.02 & 0.1 & 0.82 & 2.03 \\
& Std. dev (MW) & 0.21 & 0.14 & 0.22 & 0.38 \\
\cline { 2 - 5 } LC2 & Mean (MW) & 5.82 & 0.16 & 1.11 & 5.85 \\
& Std. dev (MW) & 0.50 & 0.22 & 0.32 & 1.25 \\
\cline { 2 - 5 } LC3 & Mean (MW) & 5.50 & 0.19 & 1.41 & 5.63 \\
& Std. dev (MW) & 0.57 & 0.26 & 0.37 & 2.43 \\
\hline
\end{tabular}


Considering that surge and pitch motions are reduced with the installation of the WEC and the tidal turbines, the unsteadiness of the inflow seen by the HWNC should become less significant accordingly. Therefore, the wind turbine energy production will become more stable. Such assumption is proved by the FFT analysis result in Fig. 12. As shown, the spectra peak value of the HWNC is just half that of the Hywind. The spectra peak is observed around $0.1 \mathrm{~Hz}$, namely the peak period of the incident wave. It indicates that the unsteadiness of the inflow is mainly caused by the inertial motions of the platform. Although the average wind turbine power output of the HWNC is not increased, it is favourable to see the improvement of the power output quality. A stable wind turbine power output is beneficial to the grid net.

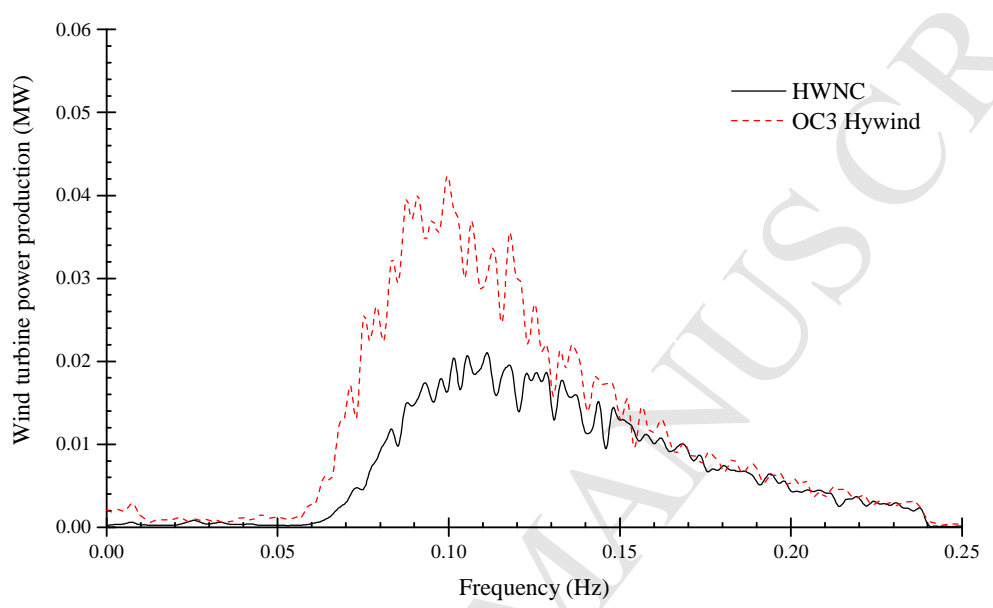

Fig. 12. FFT analysis of wind turbine power production, LC1.

\subsection{Mooring line tension}

The influence of the WEC and the tidal turbines on the mooring line tension is investigated. Table 10 summaries the statistical results of line_1 tension. The mean tensions are all increased by over $25 \%$ due to the sea current force in the three cases, and the maximum tension is as high as $1808 \mathrm{kN}$ in the simulation case LC2. It is a negative aspect of the installation of the tidal turbines.

\section{Table 10}

Statistical results of line_1 tension

\begin{tabular}{cccccc}
\hline & & Max $(\mathrm{kN})$ & Min $(\mathrm{kN})$ & Mean $(\mathrm{kN})$ & Std. dev $(\mathrm{kN})$ \\
\hline \multirow{2}{*}{ LC1 } & HWNC & 1473 & 1272 & 1361 & 28.55 \\
& OC3 Hywind & 1137 & 1050 & 1092 & 8.03 \\
\cline { 2 - 6 } LC2 & HWNC & 1808 & 1427 & 1631 & 50.24 \\
& OC3 Hywind & 1307 & 1224 & 1265 & 10.7 \\
\cline { 2 - 6 } LC3 & HWNC & 1674 & 1212 & 1433 & 55.51 \\
& OC3 Hywind & 1152 & 1045 & 1101 & 12.84 \\
\hline
\end{tabular}

While the mean tension increases, the standard deviation of the mooring line tension is augmented at the same time. Fig. 13 shows that the mooring line's response of the HWNC is much stronger. It has been pointed out that the surge and pitch motions of the HWNC are improved while the heave motion is worsened. Consequently, the strong mooring line response can be attributed to the increased heave motion of the platform. It is another negative aspect caused by the installation of the WEC. 


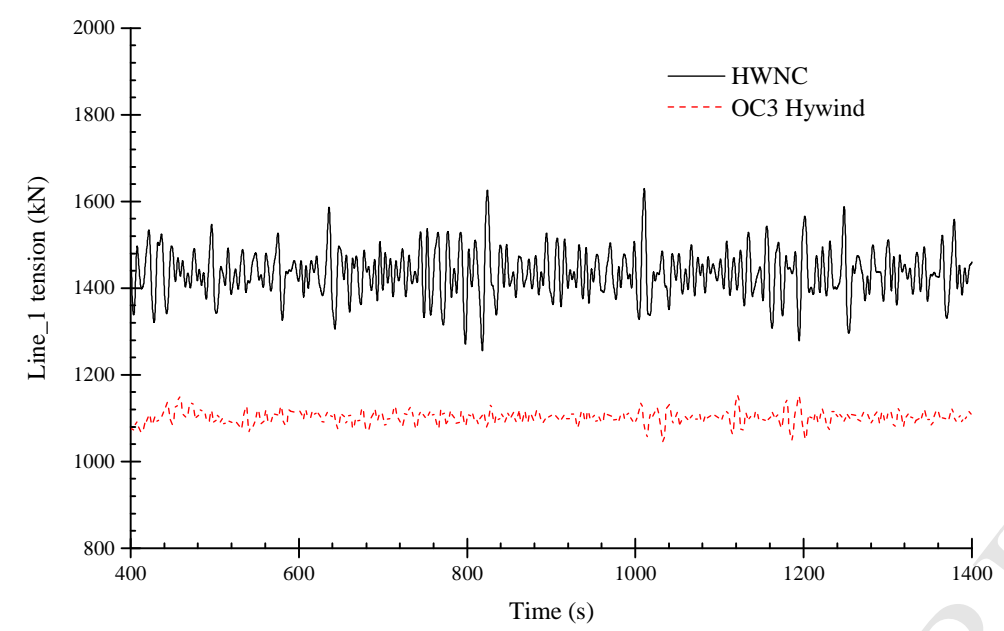

Fig. 13. Time series of line_1 tension, LC3.

Although the platform motions (surge and pitch modes) and the power output of HWNC is improved, the dynamic response of mooring line becomes worse and the maximum tension reaches a very high level. The current mooring system which is designed for a single floating wind turbine is proved not suitable for the HWNC concept. A new mooring system must be specially designed for the HWNC, which should be able to undertake very large tension. More importantly, the fatigue loads must be carefully considered in the design due to the increased standard deviation of mooring line tension.

\subsection{Transient response after emergence shutdown}

The emergency shutdown of a floating wind turbine happens occasionally due to accidental events, such as blade pitch system faults. During the short period after shutdown, the dynamic response of the floating wind turbine was found to be dominated by transient effect and large-amplitude platform motions would occur [23]. A similar problem will happen to the HWNC as well. As a result, the transient performance of the HWNC after emergency shutdown should be investigated.

It is shown that the wind turbine rotor slows rapidly and completes the shutdown in 5 seconds after the detection of the fault event. Afterwards, the wind turbine is parked and the blades are feathered to eliminate the wind force applied on the rotor. At the same time, the tidal turbines gradually slow down as well until it eventually stops after 150 seconds in order to mitigate the transient effect caused by the sudden loss of the wind turbine thrust force. 


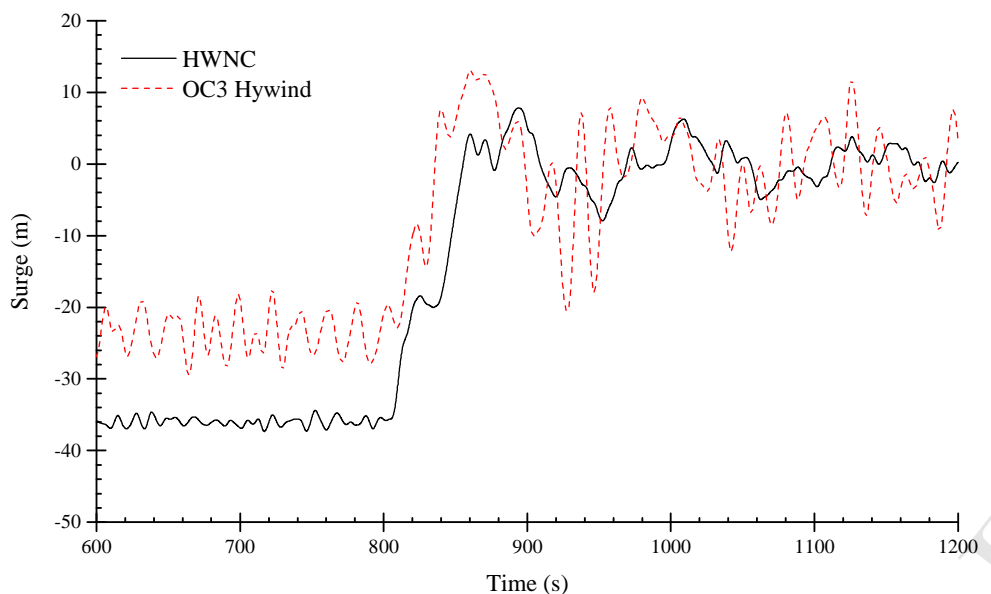

Fig. 14. Time series of surge motion before and after shutdown.

Fig. 14 plots the time series of the platform surge motion before and after the shutdown. Due to the sudden loss of the wind turbine thrust force, the mooring line tension exceeds the sea current force significantly and the platform is pulled back to a new equilibrium position. In this circumstance, the surge motion of the platform is characterised by a decay motion. As shown in Fig. 14, the Hywind undertakes large amplitude surge motion and moves back and forth around the new equilibrium position. This process can last a long period. It indicates that Hywind is very sensitive to the transient loads and it takes a long time to recover. Although a similar phenomenon is observed in the surge motion of the HWNC, the transient effect is less pronounced. According to the simulation results, the HWNC can recover from the transient effect more rapidly. It is partly due to the hydrodynamic properties of HWNC. More importantly, it is the tidal turbines that mitigate the transient loads by shutting down gradually.

\section{Conclusion}

A new offshore floating renewable energy system was proposed by integrating a floating wind turbine, a wave energy convector and tidal turbines. The primary objective of the study was to enhance the power production ability and reduce the motions of the HWNC through the combination of different types of renewable energy systems. Aero-hydro-mooring coupled analysis was performed in time domain to investigate the platform motions, power production and mooring line tension of this combined concept. Based on the numerical results, the following conclusions were drawn:

1. The surge and pitch motions of the HWNC were shown to be reduced in three operational conditions. It is mainly due to the damping force produced by the tidal turbines. Reduced platform surge and pitch motions were proved beneficial to the wind turbine power output.

2. In spite of the improved surge and pitch platform motions, the heave motion of HWNC was increased. The negative effect induced by the worsened heave motion should be further investigated. 
3. With the WEC and the tidal turbines, the overall power production of the HWNC could be increased by up to $45 \%$. The average power production of the wind turbine was just reduced less than $3 \%$ at the same time. Due to reduced platform surge and pitch motions, the quality of wind turbine power production was enhanced.

4. It was found that the mean tension of a mooring line was increased due to the sea current forces acting on the tidal turbines. Additionally, the standard deviation of the tension increased significantly with the installation of the WEC and the tidal turbines. The mooring system, which is initially designed for a single floating wind turbine, may be not applicable to the HNWC. Further study should be performed on the improvement of the mooring system.

5. The platform motions after emergency shutdown were investigated. Compared with a single floating wind turbine, the transient effect on HWNC was less significant and it recovered faster than the single floating wind turbine.

\section{Future work}

Due to the limitations of the simulation tool applied, the structural dynamics and turbine control are not considered in the study. To capture the performance of the proposed combined concept realistically, these factors should be considered in the future work. The flexible components, such as the blades and the tower, are schemed to be modelled with the beam theory.

\section{Acknowledgement}

The authors would like to acknowledge China Scholarship Council for the financial support (No. 201506230127). The support from State Key Laboratory of Ocean Engineering of Shanghai Jiao Tong University during the model test is also highly appreciated by the authors.

\section{References}

[1] F.G. Nielsen, T.D. Hanson, B.r. Skaare, Integrated dynamic analysis of floating offshore wind turbines, 25th International Conference on Offshore Mechanics and Arctic Engineering, American Society of Mechanical Engineers, 2006, pp. 671-679.

[2] Principle Power, http://www.principlepowerinc.com/, 2017.

[3] A.J. Goupee, B.J. Koo, R.W. Kimball, K.F. Lambrakos, H.J. Dagher, Experimental Comparison of Three Floating Wind Turbine Concepts, J Offshore Mech Arct 136(2) (2014) 020906. 
461

462

463

464

465

466

467

468

469

470

471

472

473

474

475

476

477

478

479

480

481

482

483

484

485

486

487

488

489

490

491

492

493

494

495

496

497

[4] P.C. Vicente, A.F. de O. Falcão, L.M.C. Gato, P.A.P. Justino, Dynamics of arrays of floating point-absorber wave energy converters with inter-body and bottom slack-mooring connections, Applied Ocean Research 31(4) (2009) 267-281.

[5] J. Engström, M. Eriksson, M. Göteman, J. Isberg, M. Leijon, Performance of large arrays of point absorbing direct-driven wave energy converters, Journal of Applied Physics 114(20) (2013) 204502.

[6] A. Bahaj, W. Batten, G. McCann, Experimental verifications of numerical predictions for the hydrodynamic performance of horizontal axis marine current turbines, Renewable Energy 32(15) (2007) 2479-2490.

[7] L. Zhang, S.Q. Wang, Q.H. Sheng, F.M. Jing, Y. Ma, The effects of surge motion of the floating platform on hydrodynamics performance of horizontal-axis tidal current turbine, Renewable Energy 74 (2015) 796-802.

[8] A. Aubault, M. Alves, A. Sarmento, D. Roddier, A. Peiffer, Modeling of an oscillating water column on the floating foundation WindFloat, ASME 2011 30th International Conference on Ocean, Offshore and Arctic Engineering, American Society of Mechanical Engineers, 2011, pp. 235-246.

[9] M.J. Muliawan, M. Karimirad, T. Moan, Dynamic response and power performance of a combined spar-type floating wind turbine and coaxial floating wave energy converter, Renewable Energy 50 (2013) 47-57.

[10] L. Wan, Z. Gao, T. Moan, Experimental and numerical study of hydrodynamic responses of a combined wind and wave energy converter concept in survival modes, Coast. Eng 104 (2015) 151169.

[11] C. Michailides, C. Luan, Z. Gao, T. Moan, Effect of flap type wave energy converters on the response of a semi-submersible wind turbine in operational conditions, ASME 2014 33rd International Conference on Ocean, Offshore and Arctic Engineering, American Society of Mechanical Engineers, 2014, pp. V09BT09A014-V09BT09A014.

[12] E.E. Bachynski, T. Moan, Point absorber design for a combined wind and wave energy converter on a tension-leg support structure, ASME 2013 32nd International Conference on Ocean, Offshore and Arctic Engineering, American Society of Mechanical Engineers, 2013, pp. V008T09A025V008T09A025.

[13] J.M. Jonkman, Definition of the Floating System for Phase IV of OC3, Citeseer2010.

[14] L. Li, Z. Hu, J. Wang, Y. Ma, Development and Validation of an Aero-hydro Simulation Code for Offshore Floating Wind Turbine, J Ocean Wind Energy, ISOPE 2(1) (2015) 1-11.

[15] C. Lee, J. Newman, WAMIT User Manual, Version 7.0, WAMIT, Inc., Chestnut Hill, MA, 2013.

[16] Z. Yu, J. Falnes, State-space modelling of a vertical cylinder in heave, Appl. Ocean Res 17(5) (1995) 265-275.

[17] M.O. Hansen, Aerodynamics of wind turbines, Routledge2015.

[18] S. Øye, Dynamic stall simulated as time lag of separation, Proceedings of the 4th IEA Symposium on the aerodynamics of wind turbines, 1991. 
498 [19] M. Hall, A. Goupee, Validation of a lumped-mass mooring line model with DeepCwind 499 semisubmersible model test data, Ocean Eng 104 (2015) 590-603.

500 [20] B.J. Koo, A.J. Goupee, R.W. Kimball, K.F. Lambrakos, Model Tests for a Floating Wind 501 Turbine on Three Different Floaters, J Offshore Mech Arct 136(2) (2014) 020907.

502 [21] A.J. Coulling, A.J. Goupee, A.N. Robertson, J.M. Jonkman, H.J. Dagher, Validation of a FAST 503 semi-submersible floating wind turbine numerical model with DeepCwind test data, Journal of 504 Renewable and Sustainable Energy 5(2) (2013) 023116.

505 [22] WEC-Sim, https://wec-sim.github.io/WEC-Sim/\#, 2017.

506 [23] Z.Q. Hu, L. Li, J. Wang, Q.H. Hu, M.C. Shen, Dynamic responses of a semi-type offshore 507 floating wind turbine during normal state and emergency shutdown, China Ocean Engineering 30(1) 508 (2016) 97-112. 


\section{Highlights}

1. This manuscript investigates the dynamic responses and power production of a newly proposed offshore floating renewable energy system, which combines a floating wind turbine, a wave energy convector and a tidal turbine.

2. Simulation program is developed to conduct the aero-hydro-mooring coupled analysis in time domain.

3. Compared with a single floating wind turbine, the combined concept undertakes reduced surge and pitch motions.

4. The overall power production is increased by approximately $20 \%$ when tidal turbine and WEC are installed. Moreover, the power production of wind turbine is found to be more stable due to reduced platform motion.

5. Besides, the combined concept is less sensitive to transient effects induced by emergency shutdown of wind turbine. 